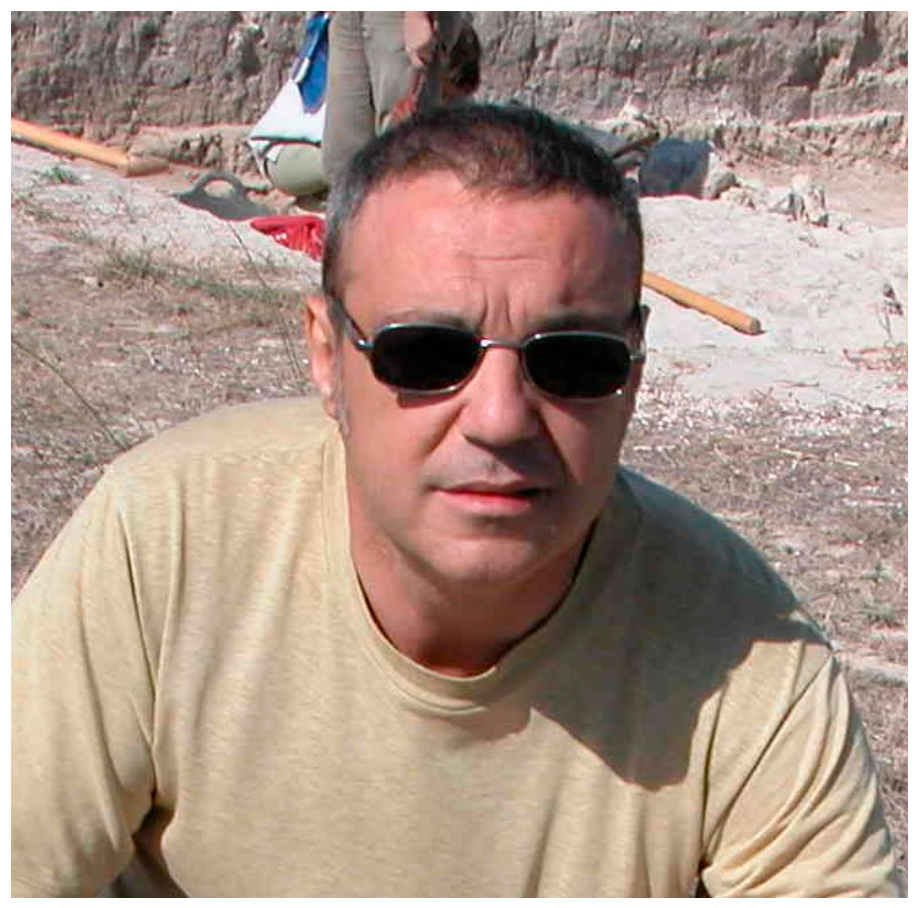

José Antonio Mínguez Morales (1962-2019), in memoriam

Borja Díaz Ariño Alberto Mayayo Catalán

El pasado 22 de mayo nos dejaba sin avisar José Antonio Minguez Morales, Profesor Titular de Arqueología en la Universidad de Valladolid y acreditado para Catedrático. Su formación se había desarrollado en la Universidad de Zaragoza, donde se doctoró en el año 1990 con una Tesis dedicada a la cerámica de paredes finas de la colonia Victrix Iulia Lepida Celsa. A partir de ese momento el estudio de la cerámica romana se convirtió en su campo de investigación predilecto, con un ramillete de aportaciones - siempre concisas, meticulosas e innovadoras- que continuarán siendo durante mucho tiempo trabajos de referencia obligada. Su prematura desaparición le ha impedido llevar a término otros proyectos de mayor envergadura como el necesario estudio sistemático de todas las producciones del famoso ceramista calagurritano Gayo Valerio Vérdulo, por el que sentía auténtica devoción.

Nosotros lo conocimos cuando todavía era Profesor Ayudante en la Universidad de Zaragoza. Tuvimos la fortuna de ser sus alumnos y comenzar a excavar con él en Bilbilis en el ya lejano verano de 1997. Fue a partir del año siguiente cuando nuestra relación empezó a volverse más estrecha, gracias a las excavaciones en La Corona (Fuentes de Ebro) y, especialmente, en La Cabañeta (El Burgo de Ebro), que en ambos casos dirigía en colaboración con el arqueólogo Antonio Ferreruela. 
Todos los que participamos en aquellas campañas veraniegas las recordamos con especial cariño, y eso se debe, sin duda, a la luminosa personalidad de José Antonio que, a menudo acompañado de su fiel perro Mórtimer, estaba siempre dispuesto a iniciar una conversación amable y distendida que hacía más llevaderas las largas y calurosas - muy calurosas- jornadas de trabajo junto al Ebro.

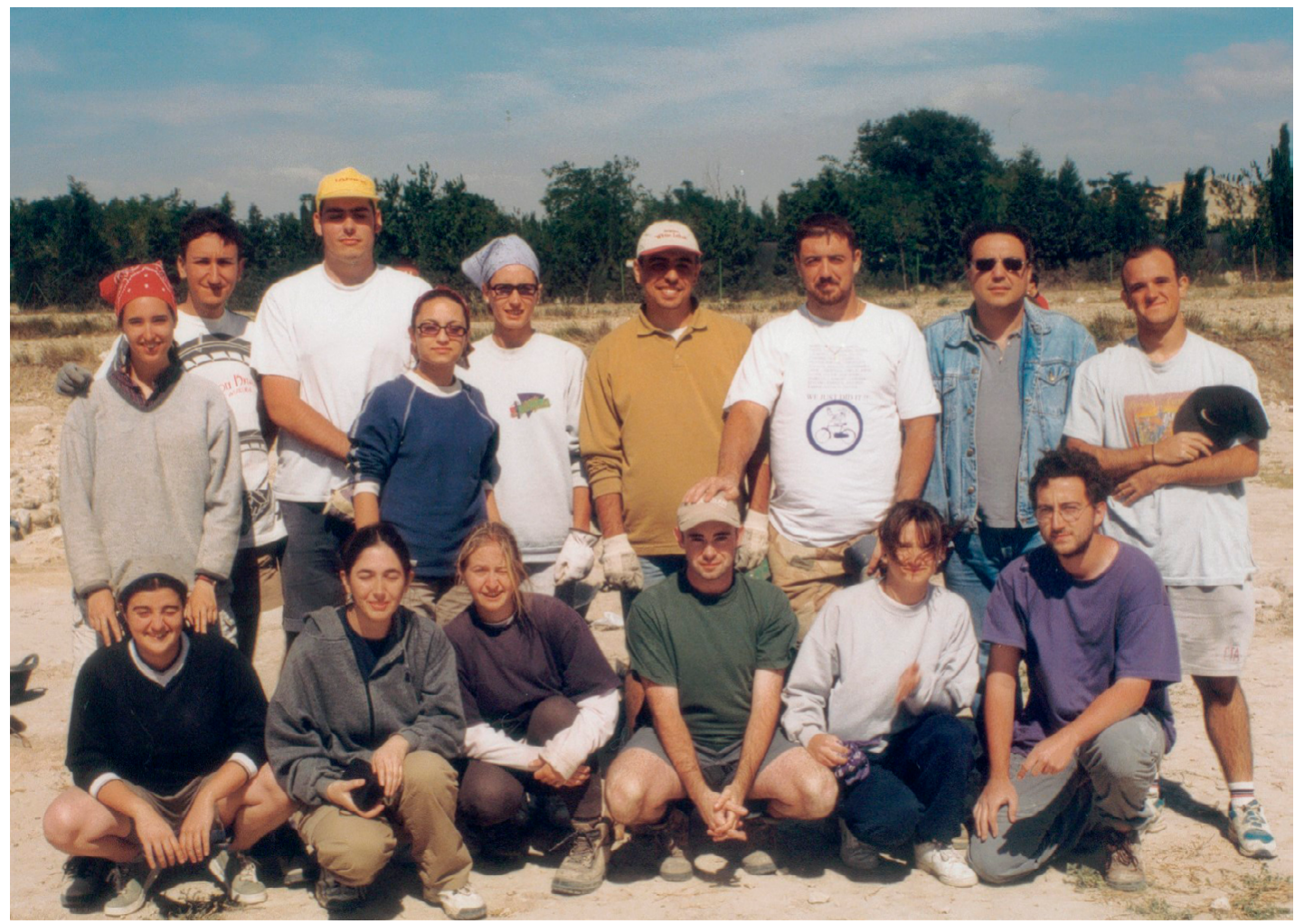

Fig. 1. El prof. Mínguez junto con el equipo excavación de La Cabañeta, verano de 2000.

Prácticamente todo lo que sabemos de Arqueología, (y de folclore, y de arte africano, y de tantas otras cosas) se lo debemos al Profesor Mínguez. En el aula, en el campo, pero, especialmente, en el laboratorio. Las largas sesiones de inventario de materiales en el viejo sótano del Departamento de Ciencias de la Antigüedad de la Facultad de Filosofía y Letras constituían, de hecho, maratonianas clases magistrales que siempre dejaban con ganas de más. José Antonio sabía mucho, pero, sobre todo, era un placer aprender de él.

Tras licenciarnos y ya con el prof. Mínguez en Valladolid nuestra relación continuó, siempre en torno a la Arqueología y a las excavaciones de La Cabañeta, que, poco a poco, y a pesar de las penurias presupuestarias, se perfilaba como un proyecto cada vez más ilusionante. 
En ese contexto, casi sin darnos cuenta, gracias a la generosidad de José Antonio, pasamos de aprendices a colaboradores, tanto en las labores de campo - en especial en las campañas de excavación de las termas romano-republicanas - como en el estudio y publicación de los jugosos materiales que proporcionaba el yacimiento.

Con su inesperada desaparición todo se ha visto interrumpido de manera abrupta. Ahora sólo nos queda estar a la altura de su magisterio y contribuir a que el trabajo que él ha liderado durante estos últimos veinte años no quede inconcluso.

José Antonio ha dejado una huella profunda en todos los que fuimos alumnos, colaboradores o amigos suyos y, en especial, en el selecto grupo de personas que tuvimos la enorme suerte de haber sido las tres cosas. $\mathrm{Su}$ marcha resulta todavía muy reciente. Le vamos a echar de mucho de menos. Sobre todo, a medida que el tiempo pase y su ausencia se haga, cada vez, más presente.

\section{Bibliografía selecta}

Los trabajos más importantes de José Antonio Mínguez responden principalmente a dos líneas de investigación claramente definidas: el estudio de la cerámica romana y el yacimiento romano-republicano de La Cabañeta. La revista Zephyrus tiene previsto publicar en su próximo volumen una bibliografía completa, incluyendo todos sus últimos trabajos, todavía en prensa. Aquí nos limitamos a ofrecer una selección de algunos de sus estudios más representativos, organizados en torno a las dos líneas temáticas antes mencionadas.

\section{Estudios sobre cerámica romana}

Mínguez, J. A., "La producción de paredes finas con decoración a molde del ceramista

G. Valerius Vedullus y su difusión en el Valle del Ebro", en: Congrés de Lezoux. Societé Française de l'Étude de la Céramique Antique en Gaule, Marsella 1989,181-189.

Mínguez, J. A., La cerámica romana de paredes finas, Zaragoza 1991.

Mínguez, J. A., "Las cerámicas de paredes finas en la colonia Lepida/Celsa (Velilla de Ebro, Zaragoza). Su relación con el territorio aragonés”, Zephyrus 44-45, 1991-92, 457-470.

Mínguez, J. A., "La cerámica de paredes finas procedente del templo romano de Córdoba. Excavaciones de 1986. Notas para su estudio", Mainake 13-14, 1991-92, 149-161.

Mínguez, J. A., "Cerámica engobada con decoración de medallones en relieve en Aragón: la forma 81.6587.A”, BSAA 61, 1995, 145-171. 
Borja Díaz Ariño | Alberto Mayayo Catalán

Mínguez, J. A., "Decoraciones fálicas sobre vasos cerámicos de época romana de la península Ibérica”, Zephyrus 49, 1996, 305-319.

Mínguez, J.A., "Paredes finas”, en: Colonia Victrix Iulia Lepida-Celsa (Velilla de Ebro, Zaragoza). El instrumentum domesticum de la Casa de los Delfines, Zaragoza 1997, 322-383.

Aguarod, M. C. y Mínguez, J. A., “Cerámica engobada”, en: Colonia Victrix Iulia Lepida-Celsa (Velilla de Ebro, Zaragoza). El instrumentum domesticum de la Casa de los Delfines, Zaragoza 1997, 447-475.

Mínguez, J. A., "La cerámica de paredes finas", en: M. Roca y M. I. Fernández (eds.), Introducción al estudio de la cerámica romana, Málaga 2005, 317-404.

Mínguez, J. A., "Las producciones de terra sigillata Sudgálica en el valle medio del Ebro", en: $\mathrm{X}$. Nieto et al. (eds.), La difusió de la Terra Sigillata Sudgàl.lica al nord d'Hispania, Barcelona 2005, 111-139.

Mínguez, J. A., "Gaius Valerius Verdullus y la fabricación de paredes finas con decoración a molde en el valle medio del Ebro. Veinte años después", en: Congreso de L'Escala-Empúries, Societé Française d'Étude de la Céramique Antique en Gaule, Marsella 2008, 181-194.

Mínguez, J. A., "La fabricación de vasos para beber de paredes finas en el valle medio del Ebro", en: D. Bernal y A. Ribera (eds.), Cerámicas hispanorromanas II. Producciones regionales, Cádiz 2012, 83-96.

Mínguez, J. A., "El consumo de cerámicas para uso doméstico en Osca durante el siglo primero de la Era: importaciones y producciones locales", Bolskan 25, 2014, 117-151.

Mínguez, J.A., "La cerámica engobada altoimperial en Aragón: contextos de consumo", en: A. Martínez, M. Esteban y E. Alcorta (eds.), Cerámicas de época romana en el norte de Hispania y en Aquitania, Madrid 2015, 423-437.

Mínguez, J. A., "Las cerámicas de paredes finas", en: E. H. Sánchez y M. Bustamante (eds.): Arqueología romana en la península Ibérica, Granada 2019, 703-716.

Mínguez, J. A., "Molde del ceramista G. Val. Verdullus para la fabricación de paredes finas encontrado en Osca (Huesca)", en: Figlinae Hispaniae. Nuevas aportaciones al estudio de los talleres cerámicos de la Hispania romana (Tarragona, 19-20 de septiembre de 2018), en prensa.

\section{Estudios sobre La Cabañeta}

Ferreruela, A., y Mínguez, J. A., "Un nuevo descubrimiento epigráfico romanorrepublicano en el valle del Ebro", en: M. Navarro y S. Demougin (eds.), Élites hispaniques, Burdeos 2001, 241-249.

Ferreruela, A., y Mínguez, J. A., "La Cabañeta (El Burgo de Ebro, Zaragoza)", en: J. L. Jiménez y A. Ribera (eds.), Valencia y las primeras ciudades romanas de Hispania, Valencia 2002, 205-214.

Ferreruela, A., Mesa J. F., Mínguez, J. A., y Navarro, M., "Una inscripción republicana de la sede de una posible Corporación en La Cabañeta (El Burgo de Ebro, Zaragoza): nuevos datos sobre la ocupación romana del valle del Ebro", AEspA 76, 2003, 217-230.

Ferreruela, A., y Mínguez, J. A., "Dos modelos de implantación urbana romanorrepublicana en el valle medio del Ebro: las ciudades de La Cabañeta y La Corona", AEspA 76, 2003, 247-262.

Ferreruela, A., y Mínguez, J. A., "Secundum oppidum quod Castra Aelia vocatur", en: A. Morillo (ed.), Arqueología militar en Hispania II: Producción y abastecimiento en el ámbito militar, León, 2006, 671-682. 
Díaz, B., y Mínguez, J. A., "Un nuevo grafito ibérico procedente de La Cabañeta (El Burgo de Ebro, Zaragoza)", PalHisp 9, 2009, 435-450.

Mínguez, J. A., y Díaz, B., "Grafitos sobre cerámica -ibéricos, latinos, griegos y signosprocedentes del yacimiento romanorrepublicano de La Cabañeta (El Burgo de Ebro, Zaragoza)", AEspA 84, 2011, 51-86.

Mínguez, J. A., y Ferreruela, A., "Las ciudades de La Cabañeta y La Corona. Su función en los inicios de la romanización del valle medio del Ebro", en: Íberos del Ebro, Tarragona 2012, 257-272.

Mínguez, J. A., "La ciudad romanorrepublicana de La Cabañeta (El Burgo de Ebro, Zaragoza) y la implantación de los modelos arquitectónicos itálicos en el valle medio del Ebro", en: J. M. Álvarez, T. Nogales e I. Rodá (eds.), Actas del XVIII Congreso Internacional de Arqueología Clásica, vol. II, Mérida 2014, 1679-1682.

Mínguez, J. A., y Mayayo, A., "Evidencias de la fabricación de lucernas en la ciudad romanorrepublicana de La Cabañeta (El Burgo de Ebro, Zaragoza)", en: R. Morais, A. Fernández y M. J. Sousa (eds.), As produçoes cerámicas de imitaçao na Hispania, II-1, Oporto 2014, 151-164.

Mínguez, J. A., "El collegium de comerciantes itálicos en La Cabañeta (El Burgo de Ebro, Zaragoza)", en: O. Rodríguez, N. Tran y B. Soler (eds.), Los espacios de reunión de las asociaciones romanas, Sevilla 2016, 347-353.

Mínguez, J. A., y Mayayo, A., "Posible área sacra localizada en la ciudad romanorrepublicana de La Cabañeta (El Burgo de Ebro, Zaragoza)”, en: J. L. Lorenzo y J. M. Rodanés (eds.), II Congreso de Arqueología y Patrimonio Aragonés, Zaragoza 2018, 203-212.

Díaz, B., y Mínguez, J. A., "Dos nuevas inscripciones latinas sobre piedra procedentes de La Cabañeta (El Burgo de Ebro, Zaragoza)", AEspA 92, 2019, 241-249.

Mínguez, J. A., "Evidencias del saqueo de época Sertoriana de la ciudad de La Cabañeta (El Burgo de Ebro, Zaragoza)", en: Cultura material romana en la Hispania republicana (Lezuza, Albacete, 22-24 de abril de 2016), en prensa

Mínguez, J. A., y Mayayo, A., "Los balnea de La Cabañeta (El Burgo de Ebro, Zaragoza): fases constructivas e inserción del edificio en la trama urbana", en: Termas públicas en Hispania, (Murcia 19-21 de abril de 2018), en prensa.

Mínguez, J. A., y Mayayo, A., "Vasos con anillo interno perforado, forma similis Consp. 51, del yacimiento de La Cabañeta (El Burgo de Ebro, Zaragoza)", en: V Congreso de la SECAH. De la costa al interior. Las cerámicas de importación en Hispania (Alcalá de Henares 6 a 8 noviembre 2019), en prensa. 